\title{
The Protective Effects of Long-term Probiotic Application on Experimental Sepsis-dependent Inflammation Process
}

(D) Sabiha AYDOĞDU1, id Murat KARAMEŞE2, id Ülkü ALTOPARLAK¹, id Selina AKSAK KARAMEŞE3

${ }^{1}$ Atatürk University Faculty of Medicine, Department of Medical Microbiology, Erzurum, Turkey

2Kafkas University Faculty of Medicine, Department of Medical Microbiology, Kars, Turkey

${ }^{3}$ Kafkas University Faculty of Medicine, Department of Histology and Embryology, Kars, Turkey

\begin{abstract}
Objective: Probiotics are defined as live microorganisms that provide beneficial effects on the host when applied in appropriate amounts. The immun-modulatory effects of some probiotics are one of these. We aimed to investigate the effects of probiotics on some inflammatory cytokine levels in sepsis.

Methods: The mixture including 12 different live-probiotic bacteria was used in this study. Group 1 and 2 were evaluated as control and sepsis groups. Sepsis was developed in groups 2, 3, 4, 7 and 8 using cecal ligation and puncture. The probiotic mixture was given to rats in groups 3 and 4 for 21 days before sepsis, groups 7 and 8 a single dose after sepsis at $10^{10}$ and $10^{11}$ doses, respectively. Rats in groups 5 and 6 , the same doses of probiotics were administered without sepsis. Interleukin (IL)-1 $\beta$, tumor necrosis factor (TNF)- $\alpha$, IL- 10 and transforming growth factor (TGF)- $\beta$ levels were measured by ELISA method.

Results: There was a serious increase on the level of TNF- $\alpha$ and IL-1 $\beta$ levels in sepsis group, and a serious decrease in 21 days of protective treatment groups. In accordance with IL-10 and TGF- $\beta$ levels, although the cytokine levels of 21 days protective treatment groups were not reached in control group, a serious increase was observed compared to the sepsis group.

Conclusion: According to our findings, probiotics can be used for supportive purposes in addition to classical medical treatment of sepsis. However, we believe that more studies should be performed in order to standardize the effects of probiotic and determine its effects with different experimental groups of volunteers as well as experimental animal studies.
\end{abstract}

Keywords: Inflammation, sepsis, cytokine, probiotic

\section{Introduction}

The sepsis and septic shock are clinical pictures that may be very serious. They develop due to the spread of microorganisms or the toxic products of these microorganisms with blood circulation. The clinical features and findings of sepsis are results of "the fight" between the immune system of the host and the microorganism and its products. Sepsis stimulates the immunological, inflammatory and endocrine systems of the host, and the severity of these responses determines the clinical course (1).

Researches on the pathogenesis of sepsis have shown that; infection and traumatic injury in tissues activate the immunological mechanisms and cause inflammatory responses by releasing some mediators (especially some cytokines). In recent studies, the physiology of sepsis has been better understood. The metabolic and physiological changes continuously developed in the body have become clearer after the cytokines and other mediators and their mechanisms of action have been identified. As a result of these studies, it was understood that sepsis syndrome is a group of response sequences in which the released cytokines are largely responsible $(1,2)$.

Under the name of "cytokine"; there are various groups of interleukins, monokines, lymphokines, growth factors, interferons

Address for Correspondence: Murat KARAMEŞE, Kafkas University Faculty of Medicine, Department of Medical Microbiology, Kars, Turkey

Phone: +90 5548638853 E-mail: murat_karamese@hotmail.com ORCID ID: orcid.org/0000-0001-7803-1462

Cite this article as: Aydoğdu S, Karameşe M, Altoparlak Ü, Karameşe Aksak S. The Protective Effects of Long-term Probiotic Application on Experimental Sepsis-dependent Inflammation Process. Bezmialem Science 2019;7(3):180-5. 
and chemokines. Cytokines are produced by a wide variety of cell types $(3,4)$. Cytokines are divided into two groups as proinflammatory and anti-inflammatory cytokines according to their mechanisms of action. While pro-inflammatory cytokines induce inflammation, anti-inflammatory cytokines prevent inflammation and promote healing $(5,6)$. The pro-inflammatory cytokines necessary for the initiation and maintenance of the immune response are released at the onset of inflammation. The most important pro-inflammatory cytokines that play a key role in immune response are tumor necrosis factor-alpha (TNF- $\alpha$ ), interleukin-1beta (IL-1 $\beta$ ), IL-6 and IL-8. TNF- $\alpha$ and IL- $1 \beta$ are the first secreted cytokines and allow secretion of other cytokines that support migration and activation of the immune cells. Secondary or assisted cytokines are IL- 6 and IL8. Anti-inflammatory cytokines are released in later stages of inflammation, regulating the inflammatory response and downregulation. The most important anti-inflammatory cytokines are IL-4, IL-10, IL-11, IL-13, and transforming growth beta factor (TGF)- $\beta$. Some cytokines may have both pro-inflammatory and anti-inflammatory effects $(1,4)$.

Experimental studies on sepsis are continuing with a great acceleration. A variety of drugs and treatment protocols involving immune-modulatory substancesare being developed. One of the immune-modulators investigated and used for these purposes is probiotic bacteria (7).

The probiotics in the human gastrointestinal tract flora are located on the surface of the intestine and prevent pathogenic microorganisms from clinging, and the antimicrobial agents they produce control the growth of these bacteria. Lactobacillus, Bifidobacterium, Streptococcus, Pediococcus, Leuconostoc and Enterococcus species have been used as probiotics. There are significant differences between probiotic bacteria species and strains in terms of their effect, however the most effective probiotic bacteria are Bifidobacterium and Lactobacillus species according to the scientific studies $(7,8)$.

Nowadays, probiotics can be used in many diseases and pathological conditions. They have beneficial effects such as strengthening the immunity of the host. Probiotics were shown to regulate immunological responses by stimulating host defense mechanisms both in in vivo and in vitro studies. It was shown in recent years that probiotics have anti-inflammatory, antioxidant, anti-bacterial, anti-parasitic, anti-fungal, apoptotic, anti-carcinogenic and many other immunological effects (7-9).

In our study, the aim was to evaluate the positive and/or negative effects of long-term probiotic use before sepsis and single/high dose probiotic administration after sepsis on TNF- $\alpha$, IL- $1 \beta$, IL10 and TGF- $\beta$ inflammatory parameters.

\section{Methods}

\section{Experimental Procedure and Animals}

This study was approved by the Local Ethics Committee of Animal Experiments with the date and approval numbers of 19.04.2016/48. Animal protocols were performed according to the local ethical rules and the rules of the Declaration of Helsinki.

Eighty female Wistar-albino rats, 12-week-old and weighing 220-300 g, were purchased. Rats were kept in polycarbonate boxes with a standard 12-hour light-dark cycle. The rats were randomly divided into 8 groups. Each group contained 10 rats (Table 1).

\section{Probiotic Mixture and Preparation}

A probiotic mixture (Enzibody ${ }^{\circ}$, Kenz BioTech, USA) that contained 12 different living probiotic bacteria strains was used in current study (Table 2). All bacteria were mixed in a 1:1 ratio. Twelve different probiotic bacteria (7 strains of Lactobacillus spp., 3 strains of Bifidobacterium spp., 1 strain of Leuconostoc spp. and 1 strain of Lactococcus spp.) were grown on de Man, Ragossa and Sharpe Broth overnight at $37^{\circ} \mathrm{C}$. Bacteria were separated from the culture supernatant by centrifugation $(15 \mathrm{~min}$ at $3000 \mathrm{xg})$, washed three times with ice-cold phosphate saline buffer (PBS) $(\mathrm{pH}=7.2)$ and re-suspended in PBS. The final concentration of mixture contained $1 \times 10^{13}$ colony-forming unit (cfu) lactic acid

Table 1. Number of animals in each group and group names

\begin{tabular}{|c|c|c|}
\hline Group & Properties & Number \\
\hline Group 1 & Control & 10 \\
\hline Group 2 & Sepsis & 10 \\
\hline Group 3 & $\begin{array}{l}\text { Septic group with } 21 \text {-day } 10^{10} \mathrm{cfu} \\
\text { probiotic application }\end{array}$ & 10 \\
\hline Group 4 & $\begin{array}{l}\text { Septic group with } 21 \text {-day } 10^{11} \mathrm{cfu} \\
\text { probiotic application }\end{array}$ & 10 \\
\hline Group 5 & $\begin{array}{l}\text { Healthy group with } 21 \text {-day } 10^{10} \mathrm{cfu} \\
\text { probiotic application }\end{array}$ & 10 \\
\hline Group 6 & $\begin{array}{l}\text { Healthy group with } 21 \text {-day } 10^{11} \mathrm{cfu} \\
\text { probiotic application }\end{array}$ & 10 \\
\hline Group 7 & $\begin{array}{l}\text { Septic group with single dose } 10^{10} \mathrm{cfu} \\
\text { probiotic application }\end{array}$ & 10 \\
\hline Group 8 & $\begin{array}{l}\text { Septic group with single dose } 10^{11} \mathrm{cfu} \\
\text { probiotic application }\end{array}$ & 10 \\
\hline
\end{tabular}

Table 2. Probiotic strains in the mixture

Probiotic bacteria

Bifidobacterium infantis

Bifidobacterium thermophilum

Bifidobacterium longum

Lactobacillus acidophilus

Lactobacillus casei

Lactobacillus paracasei

Lactobacillus helveticus

Lactobacillus plantarum

Lactobacillus bifidus

Lactobacillus brevis

Leuconostoc mesenteroides

Lactococcus lactis

ATCC: American Type Culture Collection
Strain

ATCC-15697

ATCC-25867

ATCC-1570

ATCC-43121

ATCC-393

ATCC-25302

ATCC-15009

ATCC-14917

ATCC-11863

ATCC-14869

ATCC-8293

ATCC-19435

Number

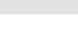

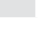

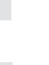


bacteria. The final concentration of $10^{11}$ and $10^{10}$ doses was obtained by $1 / 100$ and $1 / 1000$ dilution series, respectively. The mixtures were stored at $4{ }^{\circ} \mathrm{C}$ after the preparation till the day of experiment.

\section{Experiments Details and Surgical Process}

Group 1 was the "control group" and was consisted of ten rats. No surgical or treatment process was applied to group 1. Rats regularly consumed water and nutrients and blood samples were collected on the day of experiment.

Group 2 was the "septic group" and was consisted of ten rats. The rats were euthanized with $25 \mathrm{mg} / \mathrm{kg}$ dose of thiopental sodium anesthesia. After shaving the abdomen, the peritoneum was opened. The cecum was isolated and ligated with 3.0 silk ligature. The ligated part of the cecum was then punctured twice with a 16-gauge needle, and a small amount of cecal contents was expressed thought the punctures. After repositioning of cecum, the abdominal incision was closed with a 4.0 sterile absorbable suture. Blood was drawn from the apex of the cardiac ventricle, and collected into sterile blood collection tubes containing ethylenediaminetetraacetic acid after the rats were killed. Then, the blood samples were centrifuged at $4000 \mathrm{rpm}$ for 10 minutes. After centrifugation, the serum supernatant to be used for further analysis was aliquoted into microcentrifuge tubes, and stored at $-80{ }^{\circ} \mathrm{C}$.

Group 3 and 4 were the "septic groups with 21-day probiotic application" ( $10^{10} \mathrm{cfu}$ and $10^{11} \mathrm{cfu}$, respectively) and each was consisted of ten rats. $10^{10} \mathrm{cfu}$ and $10^{11} \mathrm{cfu}$ probiotic mixture were administered via oral gavage on a regular basis for 21 days to 100 $\mathrm{mg} / \mathrm{kg}$ of each animal. Then, cecal-ligation and puncture (CLP) sepsis procedure was applied on 20 rats in these groups.

Group 5 and 6 were the "healthy groups with 21-day probiotic application" ( $10^{10} \mathrm{cfu}$ and $10^{11} \mathrm{cfu}$, respectively) and each was consisted of ten rats. $10^{10} \mathrm{cfu}$ and $10^{11} \mathrm{cfu}$ probiotic mixture were administered via oral gavage on a regular basis for 21 days to 100 $\mathrm{mg} / \mathrm{kg}$ of each animal. Nothing was applied on 20 rats in these groups.

Group 7 and 8 were the "septic groups with single dose probiotic application" $\left(10^{10} \mathrm{cfu}\right.$ and $10^{11} \mathrm{cfu}$, respectively) and each was consisted of ten rats. Firstly, the CLP procedure was applied for these groups. Six hours later, single and high dose $(500 \mathrm{mg} / \mathrm{kg})$ of $10^{10} \mathrm{cfu}$ and $10^{11} \mathrm{cfu}$ probiotic mixtures were administered to evaluate the post-sepsis effectiveness of probiotic mixtures.

\section{ELISA Procedure}

To test the probiotic immunomodulation, the cytokine levels were detected by commercially available ELISA kits:

- Rat TNF- $\alpha$ ELISA kit (pg/mL) (cat no: CSB-E11987r, Cusabio, ABD).

- Rat IL-1 $\beta$ ELISA kit (pg/mL) (cat no: CSB-E08055r, Cusabio, ABD).

- Rat IL-10 ELISA kit (pg/mL) (cat no: CSB-E04595r, Cusabio, $\mathrm{ABD})$.
- Rat TGF- $\beta$ ELISA kit (pg/mL) (cat no: E-EL-R0084, Elabscience Biotechnology Ltd, ABD).

All of the chemicals and 96-well ELISA microplates were brought to room temperature before use. The first 7 wells were used for the standards; the $8^{\text {th }}$ was used for the blank, and $100 \mu \mathrm{L}$ of serum was added to each of the other wells. After incubation (at $37{ }^{\circ} \mathrm{C}$, for $90 \mathrm{~min}$ ), a $100 \mu \mathrm{L}$ biotinylated detection antibody was added to each well, and then the plate was replaced in the incubator (at $37^{\circ} \mathrm{C}$, for $60 \mathrm{~min}$ ). After a 3 step-washing, 100 $\mu \mathrm{L}$ of horseradish peroxidase conjugate was added to each well, placing the plate in the incubator again $\left(\right.$ at $37^{\circ} \mathrm{C}$, for $30 \mathrm{~min}$ ). After the final 5 step-washing, $90 \mu \mathrm{L}$ of substrate reagent was added, with 15 min incubation under darkened conditions. Finally, a $50 \mu \mathrm{L}$ stop solution was added to the wells and the plate was read at a wavelength of $450 \mathrm{~nm}$.

\section{Statistical Analysis}

The data were analyzed using the Statistical Package for the Social Sciences (SPSS) version 20.0 statistical software (IBM, SPSS, Inc., Chicago, IL, USA). Continuous variables were analyzed using the one-way ANOVA and Kruskal-Wallis tests. The differences between the groups were defined as statistically significant when the $\mathrm{p}$ value was less than 0.05 .

\section{Results}

\section{Pro-inflammatory Cytokine Results}

The level of IL-1 $\beta$, a pro-inflammatory cytokine, showed statistically significant differences in some levels among experimental groups. IL-1 $\beta$ levels were significantly increased $(146 \mathrm{pg} / \mathrm{mL})$ in sepsis group and significantly decreased in the groups treated with probiotics for 21 days before the development of sepsis $(p<0.05)$. In addition, the IL- $1 \beta$ level in the group treated with high-dose probiotic $\left(10^{11} \mathrm{cfu}\right)$ increased significantly $(\mathrm{p}<0.05)$ when compared with the control group (Figure 1). There were no statistically significant differences between sepsis and single-dose post-sepsis groups ( $p>0.05$ ).

The level of TNF- $\alpha$, which is another pro-inflammatory cytokine, in all experimental groups are presented in Figure 2. TNF- $\alpha$ levels were significantly increased (581 and $470 \mathrm{pg} /$ $\mathrm{mL}$, respectively) in sepsis groups compared with $(621 \mathrm{pg} /$

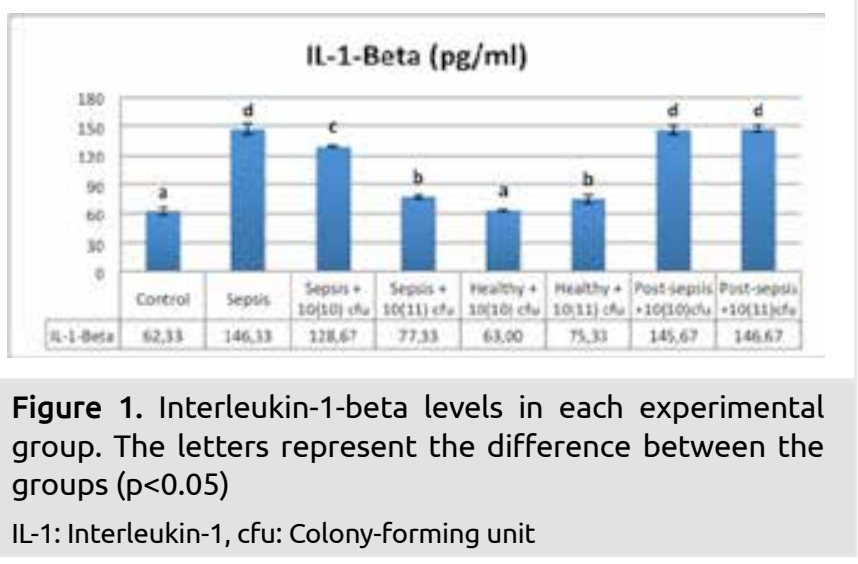


$\mathrm{mL})$ probiotic groups $(\mathrm{p}<0.05)$. TNF- $\alpha$ levels in healthy group significantly decreased when compared to the control group in a dose-dependent manner $(\mathrm{p}<0.05)$. A single dose probiotic application did not cause any significant decrease in IL-1 $\beta$ and TNF- $\alpha$ levels in post-sepsis groups ( $p>0.05)$.

After the evaluation of pro-inflammatory cytokine levels; it can be said that the present probiotic mixture suppresses excessive release of pro-inflammatory cytokines, which play an important role in the onset and permanency of the inflammatory process.

\section{Anti-inflammatory Cytokine Results}

The level of IL-10, an anti-inflammatory cytokine, showed statistically significant differences in some levels among

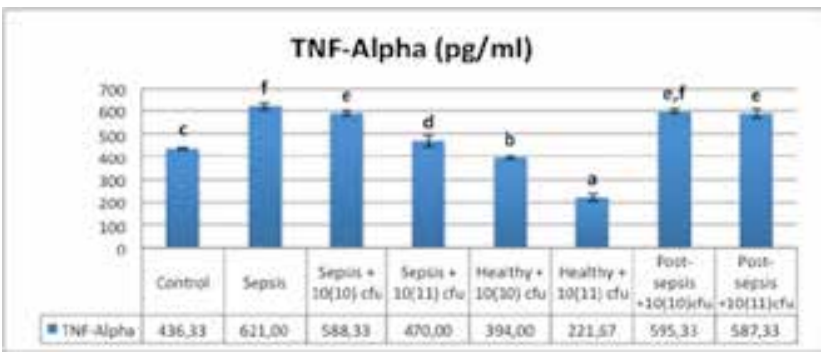

Figure 2. Tumor necrosis factor-alpha levels in each experimental group. The letters represent the difference between the groups $(p<0.05)$

TNF-alpha: Tumor necrosis factor-alpha, cfu: Colony-forming unit

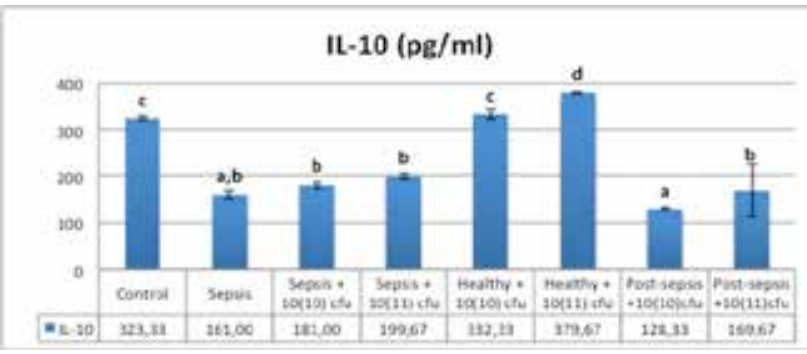

Figure 3. Interleukin-10 levels in each experimental group. The letters represent the difference between the groups $(p<0.05)$

IL-IA: İnterleukin-IA

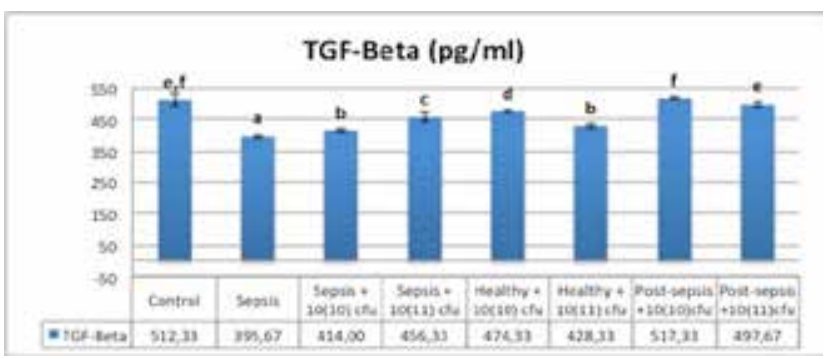

Figure 4. Transforming growth factor-beta levels in each experimental group. The letters represent the difference between the groups $(p<0.05)$

TGF-Beta: Transforming growth factor-beta, cfu: Colony-forming unit experimental groups (Figure 3). In sepsis group, the level of IL10 was the lowest among all groups $(161 \mathrm{pg} / \mathrm{mL})$, however; IL-10 levels were significantly increased in sepsis + probiotic treatment groups $(\mathrm{p}<0.05)$. In healthy groups, significant differences were observed depending on the dose manner of probiotic application. The level of IL-10 did not differ between the $10^{10} \mathrm{cfu}$ healthy group and the control group ( $p>0.05)$, however; the level of IL10 was significantly higher in the $10^{10} \mathrm{cfu}$ healthy group than in the other groups except the control group $(\mathrm{p}<0.05)$.

TGF- $\beta$ levels of all groups are shown in Figure 4. TGF- $\beta$ level was $512 \mathrm{pg} / \mathrm{mL}$ in the control group and there was a significant decrease in TGF- $\beta$ level $(395 \mathrm{pg} / \mathrm{mL})$ in sepsis group $(\mathrm{p}<0.05)$. This probiotic mixture, which we considered to be effective on anti-inflammatory cytokines in the process of inflammation caused by sepsis, resulted with an increase in TGF- $\beta$ levels (414 and $456 \mathrm{pg} / \mathrm{mL}$, respectively) in a dose-dependent manner $(\mathrm{p}<0.05)$.

When the test results were evaluated, the probiotic application used for therapeutic purposes (after sepsis) did not cause any changes, the probiotic application used for protective purposes showed differences in pro- and anti-inflammatory cytokine levels between the control group and the other groups.

\section{Discussion}

Sepsis is a serious infectious disease. Despite the developed intensive care conditions, high mortality rates have made it necessary to elaborate the mechanism of sepsis. Cytokines, which play a major role in the pathogenesis of sepsis, can be classified roughly as pro-inflammatory and anti-inflammatory mediators $(5,6)$. The cytokines that are frequently studied in experimental studies on sepsis and inflammation are TNF- $\alpha$, IL-1, IL-10 and TGF- $\beta$ (10-13).

There is excessive and irregular production of sepsis-mediated inflammatory mediators. Cytokine imbalance is seen in these inflammatory events as an increase in plasma pro-inflammatory cytokines and a decrease in anti-inflammatory cytokines (reduction in the amount of IL-10 by an increase in the amount of IL- 1 and TNF- $\alpha$ ) (14). In the light of these data, we decided to evaluate the critical pro-inflammatory (TNF- $\alpha$ and IL-1 $\beta$ ) and anti-inflammatory cytokines (IL-10 and TGF- $\beta$ ) in our study.

Today, increasingly prevalent and intensive studies on probiotics show the effects of direct or indirect stimulation of the endogenous flora and the immune system (9). Animal models and human clinical trials show that probiotics affect cytokine release and reduce inflammation $(15,16)$. The application doses of probiotics are another important point in clinical trials. Probiotic activity requires high intakes of bacteria, such as $10^{9}-$ $10^{11} \mathrm{cfu} / \mathrm{mL}$ per day, so that they can be measured significantly in humans. In our study, we benefited from available literature for probiotic doses (17).

During inflammation, macrophages and lymphocytes cause production of TNF- $\alpha$ and IL-1 which are pro-inflammatory 
cytokines. Lots of scientific studies reported higher levels of TNF- $\alpha$ and IL-1 in patient groups when compared with the healthy donors (18-20). Our results are parallel with the current literature with regards to TNF- $\alpha$ and IL-1 levels. There are some important studies that have reported the possible positive effects of probiotic usage in patients with severe and multiple traumas (21). On the other hand, a study showed that IL-10 and IL-4 levels increased in patients with severe brain trauma by using probiotic mixture containing Bifidobacterium longum, Lactobacillus bulgaricus, Streptococcus thermophilus in $3 \times 10^{9} \mathrm{cfu} /$ $\mathrm{mL}$ dose (22).

Probiotics were proven to be effective in inflammation. In experimental studies, probiotic supplementation was found to have a potential to reduce TNF- $\alpha$ expression. Lactobacillus and Bifidobacterium species were especially used in these studies same as our studies (23-25). In another studies, Lammers et al. (26) and Menard et al. (27) showed that probiotic usage can reduce the IFN- $\gamma$, IL-1 $\beta$, TNF- $\alpha$ and IL-8 levels. We also reported in the current study that the probiotic mixture reduced TNF- $\alpha$ and IL$1 \beta$ levels in sepsis groups when compared with the control group.

On the other hand, the anti-inflammatory cytokine levels, IL10 and TGF- $\beta$, are at least as important as pro-inflammatory cytokines in inflammation process. Same as pro-inflammatory cytokine results, probiotic application affects IL-10 levels in some severe conditions such as colitis. Some studies confirmed these probiotic effects and added that especially Bifidobacterium spp., Lactobacillus spp., Leuconostoc spp., and Streptococcus thermophilus were responsible of IL-10 reduction (28-30).

In our study, IL-10 level was detected at the lowest level (161 pg/ $\mathrm{mL}$ ) in the sepsis group among all experimental groups, however IL-10 levels significantly increased in sepsis groups treated with probiotic mixture. When the levels of anti-inflammatory cytokines, IL-10 and TGF- $\beta$, were examined in detail, a significant increase in the level of cytokines was observed in the sepsis-treated group. The present probiotic mixture increases the release of anti-inflammatory cytokines, which play an important role in the inflammatory process in accordance with the literature.

\section{Study Limitations}

More detailed experimental procedures should be considered. Extra methods should be used to get better results. Further studies should be carried out by performing more detailed methods. Additionally, a specific probiotic bacterium effects should be shown in further studies.

\section{Conclusion}

According to our findings, the use of probiotics decreased the levels of pro-inflammatory cytokines associated with the deterioration of sepsis pathology and increased the antiinflammatory cytokine levels which limits the inflammatory process. We believe that probiotic support can be used in addition to classical medical treatments in the treatment of sepsis, which affects all organs and systems. However, in this regard, we believe that more studies should be performed in order to standardize the effects of probiotics and to determine their effects in different experimental groups of volunteers as well as experimental animal studies.

\section{Ethics}

Ethics Committee Approval: This study was approved by the Local Ethics Committee of Animal Experiments with the date and approval numbers of 19.04.2016/48.

Informed Consent: As it was an animal experiment, only ethics committee approval was obtained.

Peer-review: Externally peer-reviewed.

\section{Authorship Contributions}

Concept: M.K., S.A., Ü.A., Design: M.K., S.A., S.A.K., Data Collection or Processing: M.K., S.A., S.A.K., Analysis or Interpretation: S.A., Ü.A., Literature Search: S.A., Ü.A., Writing: M.K.

Conflict of Interest: No conflict of interest was declared by the authors.

Financial Disclosure: The authors declared that this study received no financial support.

\section{References}

1. Cohen J. The immunopathogenesis of sepsis. Nature 2002;420:88591.

2. Hotchkiss RS, Karl IE. The pathophysiology and treatment of sepsis. N Engl J Med 2003;348:138-50.

3. Fijen JW, Muller Kobold AC de Boer P, Jones CR, van der Werf TS, Tervaert JW, et al. Leukocyte activation and cytokine production during experimental human endotoxemi. Eur J Intern Med 2000;11:89-95.

4. Al-Kharfy KM, Kellum JA, Matzke GR. Unintended immunomodulation: part I; Effect of common clinical conditions on cytokine biosynthesis. Shock 2000;13:333-45.

5. Horn DL, Morrison DC, Opal SM, Silverstein R, Visvanathan K, Zabriskie JB. What are the microbial components implicated in the pathogenesis of sepsis? report on a symposium. Clin Infect Dis 2000;31:851-8.

6. Chaudhry H, Zhou J, Zhong Y, Ali MM, McGuire F, Nagarkatti PS, et al. Role of cytokines as a double-edged sword in sepsis. In Vivo 2013;27:669-84.

7. Bergonzelli GE, Blum S, Brussow H, Corthesy-Theulaz I. Probiotics as a treatment strategy for gastrointestinal diseases? Digestion 2005;72:57-68.

8. Ashraf R, Shah NP. Immune system stimulation by probiotic microorganisms. Crit Rev Food Sci Nutr 2014;54:938-56.

9. Saarela M, Mogensen G, Fondén R, Mättö J, Mattila-Sandholm T. Probiotic bacteria: safety, functional and technological properties. J Biotechnol 2000;84:197-215.

10. Zhang A, Pan W, Gao J, Yue CL, Zeng L, Gu W, et al. Associations between interleukin-1 gene polymorphisms and sepsis risk: a metaanalysis. BMC Med Genet 2014;15:8.

11. Opal SM, Fisher CJ Jr, Dhainaut JF, Vincent JL, Brase R, Lowry SF, et al. Confirmatory interleukin-1 receptor antagonist trial in severe sepsis: a phase III, randomized, double-blind, placebo-controlled, 
multicenter trial. The interleukin-1 receptor antagonist sepsis investigator group. Crit Care Med 1997;25:1115-24.

12. Ji QW, Guo M, Zheng JS, Mao XB, Peng YD, Li SN, et al. Downregulation of $\mathrm{T}$ helper cell type 3 in patients with acute coronary syndrome. Arch Med Res 2009;40:285-93.

13. Kilic T, Ural D, Ural E, Yumuk Z, Agacdiken A, Sahin T, et al. Relation between proinflammatory to anti-inflammatory cytokine ratios and long-term prognosis in patients with non-ST elevation acute coronary syndrome. Heart 2006;92:1041-6.

14. Koca TT. Bağırsak mikroflorasının inflamatuvar hastalık patogenezindeki yeri. Arşiv Kaynak Tarama Dergisi 2015;24:78-91.

15. McFarland LV. Systematic review and meta-analysis of Saccharomyces boulardii in adult patients. World J Gastroenterol 2010;16:2202-22.

16. Ohland CL, Macnaughton WK. Probiotic bacteria and intestinal epithelial barrier function. Am J Physiol Gastrointest Liver Physiol 2010;298:807-19.

17. Karamese M, Aydin H, Sengul E, Gelen V, Sevim C, Ustek D, et al. The immunostimulatory effect of lactic acid bacteria in a rat model. Iran J Immunol 2016;13:220-8.

18. Mueller C. Tumour necrosis factor in mouse models of chronic intestinal inflammation. Immunology 2002;105:1-8.

19. Yan Y, Kolachala V, Dalmasso G, Nguyen H, Laroui H, Sitaraman SV, et al. Temporal and spatial analysis of clinical and molecular parameters in dextran sodium sulfate induced colitis. PLoS One 2009;4:6073.

20. Egger B, Bajaj-Elliott M, MacDonald TT, Inglin R, Eysselein VE, Büchler MW. Characterisation of acute murine dextran sodium sulphate colitis: cytokine profile and dose dependency. Digestion 2000;62:240-8.

21. Kotzampassi K, Giamarellos-Bourboulis EJ, Voudouris A Kazamias P, Eleftheriadis E. Benefits of a synbiotic formula (Synbiotic 2000Forte) in critically illtrauma patients: early results of a randomized controlled trial. World J Surg 2006;30:1848-55.
22. Tan M, Zhu JC, Du J, Zhang LM, Yin HH. Effects of probiotics on serum levels of Th1/Th2 cytokine and clinical outcomes in severe traumatic brain-injured patients: a prospective randomized pilot study. Critical Care 2011;15:290.

23. Peran L, Camuesco D, Comalada M, Nieto A, Concha A, Adrio $\mathrm{JL}$, et al. Lactobacillus fermentum, a probiotic capable to release glutathione, prevents colonic inflammation in the TNBS model of rat colitis. Int J Colorectal Dis 2006;21:737-46.

24. Pagnini C, Saeed R, Bamias G, Arseneau KO, Pizarro TT, Cominelli F. Probiotics promote gut health through stimulation of epithelial innate immunity. Proc Natl Acad Sci U S A 2010;107:454-9.

25. Khailova L, Frank DN, Dominguez JA, Wischmeyer PE. Probiotic administration reduces mortality and improves intestinal epithelial homeostasis in experimental sepsis. Anesthesiology 2013;119:16677.

26. Lammers KM, Vergopoulos A, Babel N, Gionchetti P, Gionchetti P, Rizzello F et al. Probiotic therapy in the prevention of pouchitis onset: decreased interleukin-1beta, interleukin-8, and interferongamma gene expression. Inflamm Bowel Dis 2005;11:447-54.

27. Ménard S, Candalh C, Bambou JC, Terpend K, Cerf-Bensussan N, Heyman M. Lactic acid bacteria secrete metabolites retaining antiinflammatory properties after intestinal transport. Gut 2004;53:8218.

28. Kühn R, Löhler J, Rennick D, Rajewsky K, Müller W. Interleukin10-deficient mice develop chronic enterocolitis. Cell 1993;75:26374.

29. Wan YM, Zhu YQ, Xia B, Luo J. Treating TNBS-Induced colitis in rats with probiotics. Turk J Gastroenterol 2011;22:486-93.

30. Helwig U, Lammers KM, Rizzello F, Brigidi P, Rohleder V, Caramelli E, et al. Lactobacilli, bifidobacteria and E. coli nissle induce pro- and anti-inflammatory cytokines in peripheral blood mononuclear cells. World J Gastroenterol 2006;12:5978-56. 